Instituto Internacional de Investigación y Desarrollo Tecnológico Educativo INDTEC, C.A.

DOI: https://doi.org/10.29394/Scientific.issn.2542-2987.2018.3.9.10.190-213

OAI-PMH: http://www.indteca.com/ojs/index.php/Revista Scientific/oai

Artículo Original / Original Article

\title{
Comunicación para el Liderazgo en las Instituciones Educativas en el Contexto de la Complejidad
}

Autores: Oscar Antonio Martínez Molina Universidad Nacional de Educación, UNAE oscar.martinez@unae.edu.ec

Oscar Alexander Martínez Villegas Instituto Internacional de Investigación y Desarrollo Tecnológico Educativo, INDTEC alexander@inteca.com Richard Antonio Martínez Villegas Instituto Tecnológico Sudamericano, TECSU rimartinez@sudamericano.edu.ec Maryuris Nakaris León Oliveros Centro Educativo Rousseau, CER maryileon@indteca.com Cuenca, Ecuador

El objetivo de la presente investigación fue analizar fenomenológicamente la forma de como el gerente-líder describe los rasgos esenciales y la forma como interactúa con sus seguidores mediante la comunicación, rasgos y actuaciones del líder responsable de una organización humana a través de su vivencia. Se enmarca en el paradigma científico cualitativo, la investigación se aproxima fenomenológicamente a la comunicación, herramienta del liderazgo responsable vivenciado por los gerentes-líderes de las organizaciones en el contexto de la complejidad. Esta aproximación partió de entrevistas en profundidad realizadas a 26 informantes de ambos sexos, de profesiones diferentes pertenecientes a los sectores público y privado. Los resultados son discutidos y analizados a la luz de teorías de liderazgo y comunicación e interpretados tomando como marco, diferentes perspectivas acerca de dichas vivencias. Se concluyó en que las características personales rasgos de comunicador efectivo, se relaciona con sus seguidores compartiendo la comunicación, mantiene unido al personal a través de la comunicación; sabe escuchar a la gente, utiliza la comunicación doble vía. Las condiciones de la organización que facilitan el liderazgo responsable estuvieron dirigidas a la existencia de una comunicación diáfana, transparente, comunicación amplia y abierta. Las propuestas a líderes noveles se orientaron a capacidad de diálogo y el uso de las TIC's.

Palabras clave: comunicación; liderazgo; organización. 


\title{
Communication for Leadership in Educational Institutions in the Context of Complexity
}

\begin{abstract}
The objective of this research was to analyze phenomenologically the way the manager-leader describes the essential features and the way he interacts with his followers through communication, traits and actions of the leader responsible for a human organization through his experience. It is framed in the qualitative scientific paradigm, research is phenomenologically approached to communication, a tool of responsible leadership experienced by the managers-leaders of organizations in the context of complexity. This approach was based on in-depth interviews with 26 informants of both sexes, from different professions belonging to the public and private sectors. The results are discussed and analyzed in the light of theories of leadership and communication and interpreted taking as a framework, different perspectives about these experiences. It was concluded that the personal characteristics of an effective communicator, is related to his followers sharing communication, keeps the staff together through communication; He knows how to listen to people, he uses double communication via. The conditions of the organization that facilitate responsible leadership were directed to the existence of transparent, transparent communication, broad and open communication. The proposals for new leaders were oriented to dialogue capacity and the use of ICTs.
\end{abstract}

Keywords: communication; leadership; organization. 


\section{Introducción}

La realidad de la complejidad dentro del mundo corporativo $u$ organizacional ha transformado la gestión de las empresas, donde lo humano pasa a ser una de las características prioritarias a considerar. Las organizaciones sociales o humanas se distinguen porque sus miembros conviven siguiendo una serie de normas positivas dirigidas a la consecución de los objetivos y otra serie de normas negativas que procuran establecer las reglas básicas de convivencia con el fin de preservar la propia existencia de la organización.

Asimismo, esta confluencia de factores positivos y negativos originan una tendencia natural al desorden de las organizaciones humanas, y para asegurar su permanencia en el tiempo debe existir un cierto grado de sentimiento de pertenencia a la misma con exclusión de los que no son miembros; es así, que el orgullo de pertenencia a una organización es lo que hace que ésta no se diluya. De manera, que, para garantizar la buena salud de una organización humana, se requiere entre otras la existencia de una comunicación dialógica, efectiva, eficiente y eficaz, diseñada para impactar tanto a lo interno como a lo externo.

De allí el interés de esta investigación de estudiar la comunicación dentro de la actuación que deben tener los líderes en estos tiempos de constantes cambios, pues van emergiendo distintos modelos de empresas para el siglo XXI, donde a decir de Martínez (2005): "subsistirán las organizaciones que efectivamente entiendan a la empresa como una organización de personas y sitúen a las personas en el corazón, centro -cuore, core- de la misma, como el activo más importante de la organización" (pág. 37); es decir, si se piensa y actúa así, entonces se estaría en presencia del liderazgo responsable ya que hacen el esfuerzo por impulsar una organización humana centrada en las personas, donde se sabe escuchar a la gente, toman en cuenta el peso o importancia de las personas en y para la empresa. 
A su vez, señala Odiardi (2004), que:

dentro del liderazgo, los líderes deben tener: Habilidad para comunicar y generar compromiso, los líderes deberían ser hábiles para comunicar, transmitir ideas claras que conduzcan eficazmente hacia los objetivos planteados, por cuanto el líder modela, comunica y motiva, los líderes deben ser un ejemplo de los demás. La credibilidad se gana minuto a minuto (pág. 70).

Bajo esta panorámica descrita, se abre todo un camino de indagación que conduce al conocimiento y abordaje de esa actividad de liderar responsablemente, desde la perspectiva misma de los actores involucrados directamente en ella: los gerentes-líderes.

El presente estudio trata de un abordaje que busca comprender cómo es la comunicación en el liderazgo responsable, en la forma como ésta es vivida y conceptualizado por esos actores, y se ubica en el ámbito de las organizaciones humanas en el contexto de la complejidad. De allí que mediante la investigación se busca como objetivo analizar fenomenológicamente la forma como el gerente-líder caracteriza o describe los rasgos esenciales y la forma como interactúa con sus seguidores mediante la comunicación, rasgos y actuaciones estas que ha de poseer un profesional para ejercer el rol de líder responsable de una organización humana a través de su vivencia, partiendo de las siguientes interrogantes:

¿Cuáles son las características o rasgos esenciales que ha de poseer un profesional para ejercer el rol de líder responsable en una organización humana en el contexto de la complejidad? y ¿Cuáles son las condiciones que ha de generar un líder responsable en su interacción comunicativa con sus seguidores, a fin de que su liderazgo sea realmente efectivo? Permitirán estas preguntas, tener acceso a rasgos actitudinales que según los gerentes-líderes a entrevistar, ha de poseer el profesional que ejerza el rol de líder responsable, así como la aproximación a aquellas condiciones que, desde la perspectiva de 
los gerentes a entrevistar, han de concebir éstos en la interacción comunicativa con sus seguidores para que su rol sea efectivo.

\section{Supuestos Teóricos}

\subsection{Las organizaciones en el contexto de la complejidad}

Para conocer la complejidad se podría iniciar con los planteamientos que hace Morín (2004), acerca de la teoría de la complejidad al considerar que es una noción a explorar... y concierne a toda organización; "la complejidad nos aparece, ante todo, efectivamente como irracionalidad, como incertidumbre, como angustia, como desorden" (pág. 2), está presente cuando hay gran número de interacciones que se traducen en acciones, incluye lo universal así como lo singular y local, existe una doble temporalidad al unísono que se contrapone a una politemporalidad donde se legan repetición, progreso y decadencia; al mismo tiempo que crece la complejidad crece el orden, el desorden, la ordenación, ésta es producto de interacciones a las que no hay que desunir, sino distinguir.

En la teoría de la complejidad, expresa Arroyo (2013), citado por Sosa (2017), quien propone que:

lo que se necesita es un nuevo conocimiento social que refleje el pasado y el presente en una perspectiva múltiple, en donde lo vertical se inserte en lo horizontal, lo particular en lo universal, lo humano en lo natural, lo local en lo global, lo individual en lo social y lo nacional en lo internacional, buscando ambos las interacciones recíprocas, las relaciones entre todas y cada una de las partes (pág. 174).

Es decir, pondera las concatenaciones e interdependencias. Igual que en las organizaciones humanas y complejas, porque en ellas todas sus partes interactúan para lograr el todo por el todo; también se entrelazan con sus pares a través de relaciones interorganizacionales en las cuales se propicia un sin número de acuerdos, convenios, cooperaciones, alianzas todo 
estratégicamente conformado donde se alinean sus objetivos para beneficio mutuo y de sus clientes tanto internos como externos.

En este orden de ideas, ninguna manifestación de la misma es aislada de las personas que la conforman, es una interacción que a juicio de Longa (2010): "son elementos concurrentes que pueden variar significativamente cuando hay hechos internos o externos que los altera, ante lo cual la teoría de la complejidad recurre a la teoría del caos" (págs. 206-208). ¿Por qué? Porque esta teoría puede inducir a error por dos motivos: (a) No necesariamente es una teoría, sino que puede entenderse como un gran campo de investigación abierto, que abarca diferentes líneas de pensamiento y (b) Caos está entendido no como ausencia de orden, sino como cierto tipo de orden de características impredecibles, pero descriptibles en forma concreta y precisa. Es decir: un tipo de orden de movimiento impredecible. Se evidencia entonces que la teoría de la complejidad y la teoría del caos se complementan.

\subsection{El Liderazgo Responsable en las organizaciones educativas}

¿Qué tipo de liderazgo requerirá una organización educativa?

Sin duda debe ser un liderazgo capaz de orientar el cambio la transformación, orientarla en función del cumplimiento de una plataforma ética, de ciertos valores de la institución, por otro lado, un liderazgo que permita por ejemplo: realizar el paso de esa organización regida por las funciones que representan la verticalidad de los cargos, a tomar en cuenta la creatividad de las personas, Pestana, Cammaroto, Neris y Canelón (2009): "el liderazgo es un factor clave en dichos procesos, y puede ser desarrollado por personas dispuestas a mejorar su calidad integral de vida y su impacto en sus equipos de trabajo" (pág. 12).

Continúa exponiendo el referido autor, que tiene que ser un liderazgo respetuoso de las diferencias, en el sentido de que cada persona tiene múltiples dimensiones: desde la dimensión corporal hasta la dimensión 
espiritual que deben ser tomadas en cuenta a la hora de respetar su actuación dentro de la empresa. Por lo tanto, el liderazgo necesario tiene que ser respetuoso de la diversidad. Tiene que ser un liderazgo que descubra en la diversidad las convergencias, es decir, que descubra que cada quien tiene una fortaleza para el proyecto global de la empresa.

En este orden las organizaciones exigen una nueva perspectiva de liderazgo porque la perspectiva tradicional de los líderes, o sea, la visión tradicional del liderazgo se basa en Senge (2005): "supuestos sobre la impotencia de la gente, su falta de visión personal y su ineptitud para dominar las fuerzas del cambio", deficiencias estas que sólo algunos "grandes líderes pueden remediar" (pág. 419).

Pero la complejidad del momento actual deberá llevar a los líderes responsables a saber manejar distintos estilos de liderazgos según la realidad de la empresa, donde la responsabilidad es lo medular de su gestión. Se acepta como válido que el líder, en su proceder básico, se incline por un determinado liderazgo, pero éste, necesariamente, deberá ir acompañado por otras maneras de ejercer el liderazgo que tengan en cuenta las variables mencionadas con una plataforma sólida de principios y valores.

El liderazgo responsable, es aquel que se ejerce para beneficio de los demás, y donde el líder motiva y anima a las personas basado en su propio ejemplo. Acevedo (2011):

El liderazgo responsable se caracteriza por el servicio, la dirección, el apoyo, la comprensión, la amistad y el amor, hacia los demás, bajo principios éticos, morales y espirituales en los que se persiga el bien común sin afectar a terceros, es decir, que el fin no justifica los medios (párr. 8).

\subsection{La Comunicación en el Liderazgo Responsable}

La capacidad de comunicar según Baldoni (2003a):

es la herramienta más efectiva del líder, porque un líder puede obtener grandes logros con palabras, sin embargo, las palabras 
por si solas no son más que una información; además si estas son potenciadas por el carácter del líder, su convicción y su ejemplo personal, las palabras pueden adquirir el poder de comunicar, vale decir, informar, exhortar, animar, curar o inspirar. Pareciera sencillo elaborar un mensaje a primera vista a otra persona, escuchar su feedback y continuar entendiéndose mediante la comunicación, sin embargo, es uno de los cometidos más complicados del líder (pág. 1).

Razón por la cual, Zenger (s.f.): señala en su entrevista que "la gran asignatura pendiente de los líderes, especialmente el español fundamentalmente es el establecimiento de objetivos y todo lo que tenga que ver con el eje interpersonal: construir relaciones, trabajar en equipo y comunicarse adecuadamente" (pág. 1).

Retomando lo planteado, para lograr la elaboración de mensajes hay que analizar tres etapas de un proceso de comunicación de liderazgo: (a) Se desarrolla el mensaje o lo que se quiere decir o hacer; (b) Se comunica el mensaje verbal, mental y metafóricamente y (c) Se respalda el mensaje manteniéndolo fresco (dinámico, fluido) y significativo (signos y símbolos comunes). Baldoni (2003b): evidencia entonces, como se "puede contribuir a mejorar las palabras orales y escritas en mensajes de liderazgo que informen, exhorten e inspiren a los demás a mejorarse a sí mismo, a su equipo y a su organización" (pág. 1).

Cabría preguntarse: ¿Cómo se comunica un líder? El Teórico de la Comunicación Empresarial Baldoni (2003c): ha contribuido a dar respuestas en el sentido que hacen señalamientos donde destacan que "las comunicaciones de liderazgo están compuestas por mensajes del líder que se fundamentan en los valores y la cultura de una organización y tienen una importancia para los empleados o seguidores, clientes, socios estratégicos, accionistas y medios de comunicación" (pág. 2).

Si se revisa como influyen las comunicaciones en la organización se 
puede generalizar que es de manera descendente o de arriba hacia abajo, sin embargo, para completar este proceso de comunicación los lideres deben hacer algo importante y adquirir el compromiso de escuchar, es decir, establecer un clima propicio para el intercambio de ideas, fijar sus expectativas en torno a realizarlo tanto de manera individual como con los equipos de trabajo y estructurar sus comunicaciones para mantenerlos fieles a la cultura organizacional.

\section{El Camino del Método}

\subsection{Paradigma Fenomenológico para llegar a la realidad buscada}

Una vez presentadas las características del problema, las interrogantes formuladas y la teoría referencial, las cuales vinculan el presente estudio con el denominado paradigma científico cualitativo. Cabe destacar que desde el punto de vista metodológico, el análisis efectuado fue esencialmente fenomenológico, que buscó la comprensión inmediata del mundo vital de los hombres y mujeres a través de la interpretación global de las situaciones por ellos vividas, como la descripción de la estructura esencial de la experiencia y sus objetos -tomando imágenes destacadas de la conciencia para penetrar en las capas de la experiencia- con el objeto de aprehender la estructura del fenómeno tal como se muestra, e investigar sus bases y sus orígenes comparativamente como se experimenta, destacando las formas posibles como él es percibido por los individuos (Husserl, 1859-1938), citado por (James, 1999, pág. 296).

Los momentos del método fenomenológico seguidos en el presente estudio, propuestos por Leal (2003):

(a) Momento Psicológico (las representaciones presentes en el material de análisis reflejan el punto de vista del (los) individuos que se investigan); (b) La lógica del significado (la vivencia se vuelve objeto en la medida en que hace visible -muestra- algo 
esencial (universal); (c) Constitutivo trascendental (se buscan correspondencias mutuas que puedan volverse más nítidas al describirlas o si la reflexión las ha descubierto); (d) Metafísico de la conciencia (se procura comprender la conciencia fundamental o conciencia constitutiva del todo y se pasa a la Reflexión general); y (e) El histórico crítico (se plantea el horizonte social, yendo por comparación a lo teórico previamente establecido). (pág. 56).

\subsection{Perfil de los gerentes-lideres entrevistados}

El total de entrevistados fueron 26 gerentes-líderes, de ambos sexos, diferentes profesiones y mayor de cinco (5) años de experiencia en su desempeño, así como pertenecientes a diversas áreas: sociales, económicos e industriales vinculadas tanto al sector público como privado. Es necesario acotar que alguno de los informantes (gerentes) están distribuidos geográficamente: 25 en Venezuela y uno (1) en Argentina, residenciados en las ciudades de Caracas, Maracaibo, Porlamar, San Cristóbal, Trujillo, Valera, Valencia y en Buenos Aires respectivamente. Las vivencias de las unidades informantes fueron obtenidas a través de entrevistas en profundidad focalizadas de manera individual y grupal.

\subsection{Entrevista en profundidad-focalizada}

Al total de informantes se les hizo la entrevista individual alcanzando un número de diecinueve (19) de manera individual y a siete (7) de forma grupal, la misma, requirió de grabación de audio, utilizando un grabador digital, que automáticamente asignó códigos a cada una de las grabaciones, la cual tuvo una duración aproximada de cincuenta (50) minutos a una (1) hora, y se orientó por el guion diseñado para tal fin. 


\section{Análisis e Interpretación de la Realidad}

\subsection{Resultados sobre Significado de Liderazgo Responsable}

Los liderazgos responsables se caracterizan eidéticamente por estar dirigida a un elemento sobre el que se basa un conocimiento o significado hacia elementos primariamente racional-cognitivo, implicados en la noción de liderazgo responsable que ha construido y que manejan los gerentes-líderes que es concebida como aquel relacionado con características del líder responsable. Este significado de liderazgo responsable -en el que está implicado el mundo social- coexisten una serie de esencia de significados o elementos eidéticos que se relacionan con su hacer a su vez dio como resultado un significado que siguen dos tendencias:

Aquel relacionado con características del líder responsable, y que tiene que ver con; Compartir con los seguidores la comunicación, Mantener unido al personal a través de la comunicación, Trabajar de manera integrada y comunicando, son algunas de las expresiones verbales, tal como se evidencia en las expresiones de los informantes:

Informante nro. 1: ... un liderazgo responsable es un compartir... es compartir con los seguidores e interactuar con ellos; ...compartimos una comunicación doble vía, ellos me dan feedback donde exponen sus puntos de vista de la organización, pero ellos también como yo piensan en la empresa para que se cumplan las metas...

Informante nro. 2: ...el liderazgo responsable para mi es saber conformar un equipo de trabajo, mantenerlo unido, hablarle, en dialogar, en hacer reuniones periódicas y constantes, en una comunicación bidireccional, en autorizarle que me den feedback y que no sientan temor de hacerlo porque si estoy fallando en algo díganmelo...

El liderazgo que se responsabiliza con el cliente interno y externo y las expresiones se ubicaron en: hay que saber escuchar a la gente, comunicación de doble vía. Tal como evidencian las siguientes: 
Informante nro. 3: ...siempre he tenido como objetivo que el líder responsable tiene como meta la integración con el resto del equipo y a través de la comunicación doble vía es posible superar o sobrepasar dichas metas si uno oye a su equipo y le da retroalimentación...

Informante nro. 4: ...dentro de la realidad empresarial es muy importante la comunicación con los clientes tanto internos como externos porque también el saber escuchar es definitivamente lo que permite que tengamos una visión más completa... entonces escuchar ...es una herramienta extremadamente poderosa sobre todo en ambientes tan difíciles como el que estamos viviendo...

\subsection{En relación con las Características que ha de poseer el Líder Responsable}

Sobre la base de la experiencia de los informantes, es claramente reconocida por ellos, que el líder responsable debe tener ciertas características o rasgos de ánimo sentido y percibido en cuanto a que sea comunicativo, que utilice la comunicación doble vía, que sepa escuchar, presentan expresiones como las siguientes:

Informante nro. 5: ...Debe ser un comunicador, es decir, que utilice la comunicación doble vía, que sepa escuchar, que tenga un alto valor de la ética y con unos principios bien arraigados de honestidad, que promuevan la participación de las personas y sus seguidores o su equipo, que orienten procesos de aprendizaje y adaptación a esos cambios producto de la incertidumbre que viven las organizaciones en la actualidad y que se llama Complejidad, que tenga bien alto el principio de identidad con la organización...

Informante nro. 6: ...este... bueno el desempeño fundamentado en valores, comunicación, es vital que el líder se comunique y si tú no tienes esas características personales como comunicación, porque la comunicación, es lo 
que te da la oportunidad de poder conocer, de saber escuchar, conocer bien a las personas para darle un trato personalizado y eso te lo permite si tu como líder tienes ese rasgo...

\subsection{Resultados sobre Condiciones de la interacción del líder con sus seguidores}

Las condiciones o escenarios que ha de generar a fin de que su liderazgo sea realmente efectivo estuvieron dirigidas a condiciones que facilitan las relaciones un líder responsable en su interacción con sus seguidores, entre las cuales identifican existencia de una comunicación doble vía, escucha activa, apertura y disposición a las críticas. Por ejemplo:

Informante nro. 6: ...bueno lo importante, lo primero,... lo primero que se debe dar como condición, y ya te lo dije anteriormente es una excelente comunicación doble vía, en un escenario así que tu como líder te comunicas con tus seguidores o tu equipo, ...también producto de lo anterior, un nivel de confianza y apertura que no te vean como a un jefe, sino como a una persona que orienta y democráticamente se tomen decisiones y ese nivel de identificación y lealtad a la empresa, ayuda...

Informante nro. 4: ... Hay que ser un comunicador de doble vía y buen oyente si se quiere ser un líder responsable, porque aparte de la formación que uno trae yo entré en este mundo profesional. digo yo cuando estábamos tratando de entrar en la gerencia moderna, en la gerencia moderna donde me enseñaron que debo. debo oír a todo el personal e inclusive he tratado de practicarlo siempre...

\subsection{Resultados sobre Condiciones de la organización}

Estas condiciones están referidas al ambiente y la estructura se pretende la aproximación a aquellas condiciones que, desde la perspectiva de los gerentes entrevistados, han de generar en éstos el conocimiento que 
tengan acerca de la organización que lideran y de los objetivos perseguidos para que su rol sea efectivo. Con respectos a la misma, estuvieron dirigidas las vivencias a la existencia de condiciones que favorecen tales como comunicación diáfana, transparente, comunicación amplia y abierta en dos vías, entre otras fueron sus expresiones, por ejemplo:

Informante nro. 7 : ... Las condiciones... (piensa en la respuesta) ....En el escenario debe privar la comunicación diáfana, transparente, de dos vías como elemento fundamental para que tú como líder puedas comunicar, pero tus seguidores, ellos puedan retroalimentar el proceso y además sentirse atendidos, eso es muy importante, que ellos puedan... la comunicación tiene que ser en dos vías, para un líder eso es muy importante.

Informante nro. 8: ...La comunicación, amplia, abierta en dos vías, una comunicación doble vía, yo les digo, ellos me dicen, yo planteo, ellos plantea y las decisiones de mutuo acuerdo y si hay decisiones en las que yo pienso se debe hacer como digo yo, explico el por qué, escucho las propuestas de ellos y las analizamos para ver, porque yo puedo estar... estar también pelando, porque de pronto ver algo que te traen, por eso se dice que todos los días se aprende algo nuevo, todos los días se aprende algo nuevo.

\subsection{Resultados sobre Factores internos (locus of control) que inciden en el Liderazgo Responsable}

Los factores internos locus of control que inciden en el Liderazgo Responsable definitivamente repercuten en mayor grado, sobre la actuación de los gerentes-líderes y que según ellos favorecen su labor, quienes reconocen e identifican esencialmente en ellos, los factores internos que inciden positivamente o favorecen, se han hecho sentir en aspectos como: Comunicación doble vía, Capacidad de diálogo y el uso de las TIC'S. A continuación, algunos testimonios.

Informante nro. 9: Otro factor interno positivo que se debe tener en 
cuenta es la comunicación doble vía, el saber escuchar y en el buscar el momento oportuno para ...para generar una información, porque no siempre en todos los sitios tú puedes dar información y es una de las fallas fundamentales en la gestión de un gerente. líder, porque a veces no evalúa el entorno, tú sabes que la comunicación se basa en tres grades elementos a considerar: el emisor, el receptor y la vía de comunicación, si esos no están totalmente sincronizados, alineados, definitivamente la comunicación no va a llegar como se espera que tiene que llegar, resumo debe haber una excelente comunicación...

Informante nro. 10: ...En primer lugar la comunicación es clave, todo líder basa el ejercicio de su liderazgo en el aspecto comunicacional, una buena comunicación será la clave para transmitir el mensaje que el líder quiere inculcar en sus seguidores para lograr los objetivos organizacionales y algo muy importante que favorece es el uso de las TIC'S como herramienta básica para la comunicación síncrona y asíncrona facilita dicho ejercicio...

\section{Propuestas vinculadas al que hacer.}

Los gerentes-líderes entrevistados, identificaron claramente aquellos elementos que según su propia experiencia perturbaron su labor como líderes responsables para hacer propuestas o recomendaciones válidas a los líderes naturales, quienes se inician en la gestión empresarial, recomendaciones dirigidas para el líder como persona (perfil personal).

Con respecto al perfil personal hicieron señalamientos en cuanto a: comunicarse, y desarrollar habilidades de comunicación, tener la mente clara, tener sentido común:

Informante nro. 11: ...debe saber escuchar, debe ser tolerante, comunicador y observador nato. Debe ser investigador con habilidades para el manejo de las TIC'S, así como mantenerse actualizado, es decir, prepararse académicamente... 
Informante nro. 10: ...lo importante es conocer en profundidad a cada uno de los integrantes de cada equipo.... ser buen oyente, que es una característica-apúntala- que debe tener el líder responsable, tratar de oír y entender y luego de todas las opiniones es tratar de integrar una que casi siempre es la excelente, porque si uno cree que tiene la respuesta, lo que está es pelando...

\subsection{Comparación con las teorías sobre comunicación y liderazgo en el cual está enmarcado el liderazgo responsable}

Los resultados de esta investigación de carácter cualitativo y fenomenológico se entretejen en cuanto a que los gerentes-líderes tienen un significado de liderazgo responsable en el que está implicado el mundo social que está relacionado con las características propuestas por los referidos autores, donde se evidencia que coinciden este aspecto donde se perfiló a que tiene que ser un liderazgo donde prevalezca como rasgo principal el ser un buen comunicador, que descubra en la diversidad las convergencias, es decir, que descubra a través de su diálogo y escucha activa que cada quien tiene una fortaleza para el proyecto global de la empresa, además un liderazgo respetuoso de las diferencias, en el sentido de que cada persona tiene múltiples dimensiones: desde la dimensión corporal hasta la dimensión espiritual las cuales deben ser tomadas en cuenta a la hora de respetar su actuación dentro de la empresa.

También son coincidentes desde el punto de vista de Baldoni (2003d): en el sentido que hacen señalamientos donde destacan que "las comunicaciones de liderazgo están compuestas por mensajes del líder que se fundamentan en los valores y la cultura de una organización y tienen una importancia para los empleados o seguidores, clientes, socios estratégicos, accionistas y medios de comunicación" (pág. 2).

A su vez, el liderazgo responsable crea un vínculo de confianza entre el 
líder y sus seguidores, así como lo expresa Baldoni (2003e): quien indistintamente asume que lo que persigue con las comunicaciones el líder, es "afirmar la misión y la visión de la organización, poner en marcha iniciativas de transformación para el logro de las metas organizacionales" (pág. 2).

\section{Reflexión Final}

El presente estudio de carácter cualitativo abordó la comunicación presente en la actuación del líder responsable como objeto de percepción y vivencia para un grupo de veintiséis gerentes-líderes que se desempeñan en diferentes sectores tanto público como privado del país y uno de Argentina, sobre la base de sus intervenciones verbales a este respecto. En las referidas intervenciones expuestas dentro de un marco esencialmente cualitativo fenomenológico y discutido a la luz de planteamientos derivados de investigaciones sobre el tema en cuestión, diversas fuentes teóricas, y mediante el análisis de sucesivas reducciones fenomenológicas de esa misma naturaleza.

Todo ello condujo a la mostración del significado o noción del liderazgo responsable relacionado con las características personales; así como se responsabiliza con el cliente interno y externo; también deben existir unas condiciones facilitadoras o prevalecientes con los seguidores, como unas condiciones del ambiente y estructura; además unos factores internos que facilitan el liderazgo responsable y por último unas recomendaciones 0 propuestas para el líder natural que se inicia, donde el centro medular de ese análisis es la manera como la comunicación forma parte privilegiada del liderazgo responsable, todo ello pone en evidencia que se trata de una vivencia real y explicable.

Las características personales propias como comunicador, su responsabilidad con los seguidores y la organización, así como esa capacidad para la escucha activa, el manejo de los mensajes entre otras, representa 
entonces el desafío de trabajar sobre la idea de contar con líderes en todos los niveles orientando u orientados tras una clara e internalizada Visión y la creación de futuros, que configuren diseños de organizaciones acordes, estimulen la cooperación y el trabajo en equipo, valoricen el conocimiento y el aprendizaje permanente. Se trata entonces, de crear o consolidar una cultura abierta, flexible y compartida con foco en los resultados, los desempeños, las personas y el desarrollo de nuevos líderes que comuniquen, para ello los líderes efectivos advierten el carácter estratégico de la comunicación en los procesos de cambio, el desarrollo de redes de conversaciones en el interior de sus organizaciones y en su relación con el contexto, orientadas a los resultados, características presentes en las organizaciones humanas.

\section{Referencias}

Acevedo, N. (2011). Cuando se pierde el Liderazgo. Venezuela: WordPress.com - Innovación 3000. Recuperado de:

https://nelsonacevedo72.wordpress.com/2011/06/23/cuando-sepierde-el-liderazgo/

Arroyo, G. (2013). La transversalidad como camino del conocimiento complejo, y la formación ecológica. Siglo XXI: complejidad y Relaciones Internacionales, México: Grupo Editorial Cenzontle, págs. 107.

Baldoni, J. (2003a,b,c,d,e). Los secretos de Comunicación de los Grandes Líderes. New York City. Editorial McGraw-Hill Trade, ISBN: 0071414967, págs. 208. Recuperado de:

https://wrightcompany.files.wordpress.com/2012/03/secretos-decomunicacion-de-grandes-lideres summarie.pdf

James, B. (1999). Historia y Sistemas de la Psicología. ISBN: 970-1702514. México: PRENTICE HALL, págs. 392.

Leal, N. (2003). El método fenomenológico: principios, momentos y 
reducciones. En Revista Arbitraje, 1(2), 51-61. Venezuela: Universidad Experimental Simón Rodríguez.

Longa, V. (2010). Las teorías del caos, la complejidad y los sistemas. Impactos educativos y aplicaciones en ciencias sociales, de Eduardo Alejandro Ibáñez. Teorema: Revista internacional de filosofía, 29(3), 206-209, ISSN: 0210-1602. Recuperado de: https://dialnet.unirioja.es/servlet/articulo?codigo $=4350872$

Martínez, J. (2005). Las personas en la organización. Equidad \& Desarrollo, (3), 35-43, ISSN-e: 2389-8844, ISSN: 1692-7311. Recuperado de: https://dialnet.unirioja.es/servlet/articulo?codigo $=5166521$

Morín, E. (2004). La Epistemología de la Complejidad. Gazeta de Antropología, (20), 1-15, Artículo 2, ISSN: 0214-7564. Recuperado de: http://hdl.handle.net/10481/7253

Odiardi, L. (2004). El significado psicológico del liderazgo en cuatro grupos de ejecutivos mexicanos, usando Redes Semánticas. Tesis. México, D.F.: Universidad Iberoamericana. Recuperado de: http://www.bib.uia.mx/tesis/pdf/014377/014377.pdf

Pestana, F., Cammaroto, A., Neris, L., \& Canelón, E. (2009). Liderazgo transformacional y gestión educativa en contextos descentralizados. Actualidades Investigativas en Educación, 9(2), 127. Recuperado de: https://doi.org/10.15517/aie.v9i2.9540

Senge, P. (2005). La Quinta Disciplina: El arte y la práctica de la organización abierta al aprendizaje. 2da. Edición, 4ta. Reimpresión. Buenos Aires, Argentina: Granica, ISBN: 950-641-430-0.

Sosa, S. (2017). La complejidad del mundo actual y las nuevas teorías y epistemologías en la enseñanza de Relaciones Internacionales: el legado de la obra de la doctora Graciela Arroyo Pichardo. Revista de Relaciones Internacionales de la UNAM, (128), 165-179. Recuperado de: 


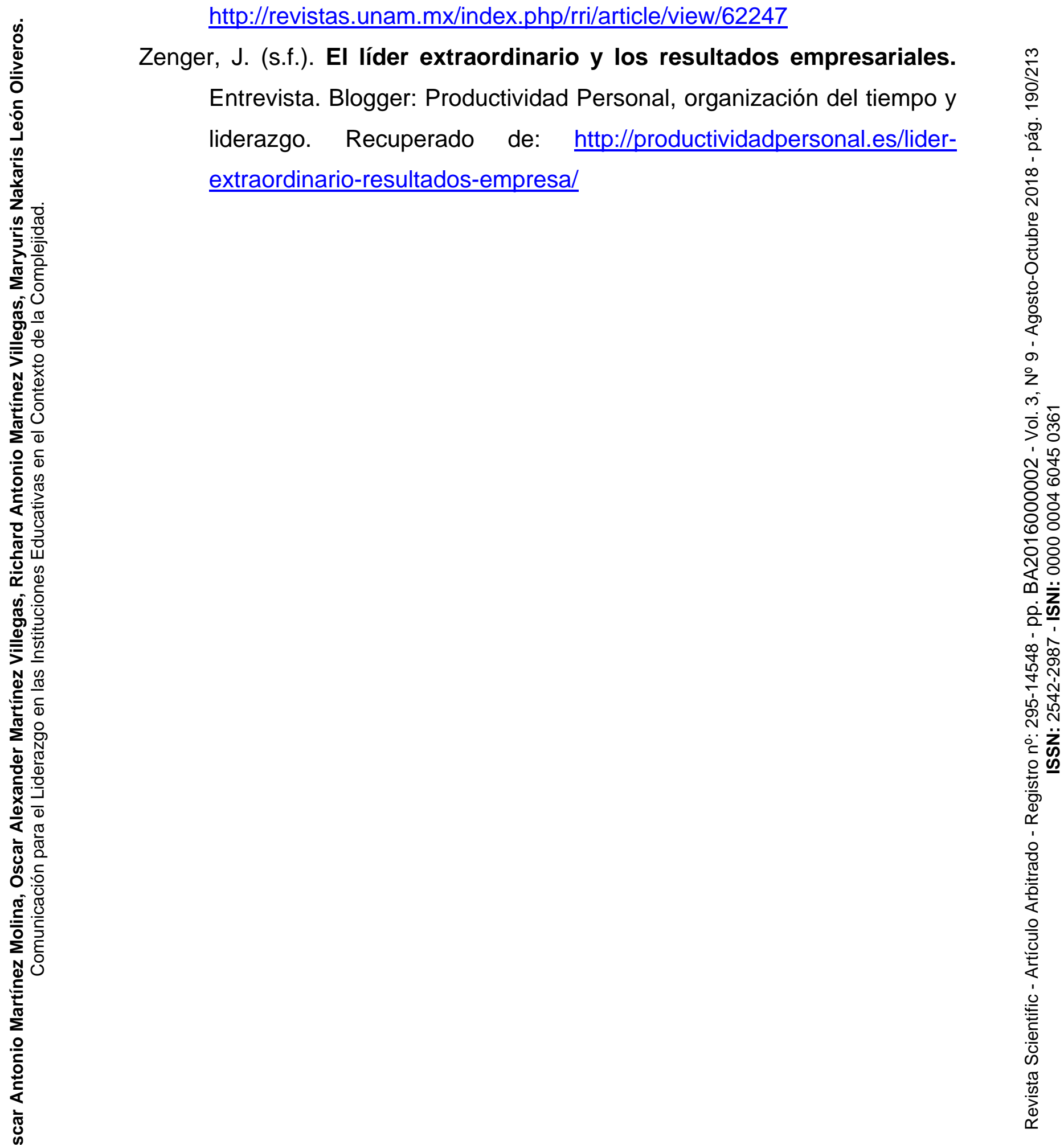




\section{Oscar Antonio Martínez Molina \\ e-mail: oscar.martinez@unae.edu.ec}

Nacido es San Cristóbal, estado Táchira, Venezuela.

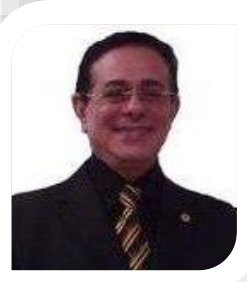

Residenciado en Cuenca, Ecuador. Licenciado en Educación Mención Orientación Educativa y Profesional (Universidad de Los Andes, Extensión Táchira). Magíster en Ciencias de la Educación Superior, Mención Andragogía (UNELLEZ). Doctor en Educación Mención Suma Cum Laude (Universidad de Málaga, España), Postdoctor en Estudios Libres de la Universidad Fermín Toro. Diplomado en Educación Abierta y a distancia (Universidad Fermín Toro). Maestría Experto avanzado en E-learning en la Fundación para la actualización tecnológica de Latinoamérica (FATLA). Maestría Experto en Tecnología Educativa nivel avanzado en la Fundación para la actualización tecnológica de Latinoamérica (FATLA). Profesor Jubilado de la Universidad Nacional Abierta. Categoría Académica de Titular. Director de tesis doctorales y de maestría. Responsable de la línea en enseñanza-aprendizaje de investigación del COBAIND. Representante del convenio Editorial Académica Española-COBAIND. Coordinador de la línea de investigación en Educación en la UNEFA Barinas. Presidente/Fundador del Consejo Barinés de Investigación y Desarrollo. Profesor investigador del Programa de Estímulo a la Innovación e Investigación en categoría "A-2". Docente investigación de la Universidad Nacional de Ecuador. 


\section{Oscar Alexander Martínez Villegas}

e-mail: alexander@indteca.com

Nacido en Barinas, estado Barinas, Venezuela.

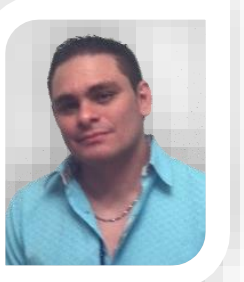

Residenciado en Cuenca, Ecuador. Estudios: Ing. de Sistemas; Consultor Técnico en Criminalística (Universidad de Carabobo, FUNDACID-CLADIJ-UC); Experto en Educación Virtual (Fundación para la actualización tecnológica de Latinoamérica, FATLA); Experto en Tecnología Educativa EDUCATE 3.000 (FATLA); Experto en Administración WEB (FATLA); Experto en Medios y Periodismo Digital (FATLA); Técnico en Higiene y Seguridad Industrial (EAO-Barinas); Técnico en Emergencia Industrial (EAO-Barinas). Representante Legal del Instituto Internacional de Investigación y Desarrollo Tecnológico Educativo INDTEC. 


\section{Richard Antonio Martínez Villegas}

e-mail: rimartinez@sudamericano.edu.ec

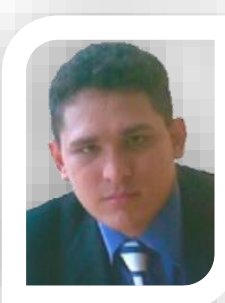

Nacido en Barinas, estado Barinas, Venezuela.

Residenciado en Cuenca, Ecuador. Estudios: Licenciado en Educación Mención Integral (Universidad Nacional Experimental de Los Llanos Occidentales Ezequiel Zamora, UNELLEZ, Barinas, estado Barinas); Experto en Educación Interactiva y a Distancia (Universidad Fermín Toro, UFT); Docente y Coordinador (Universidad Pedagógica Experimental Libertador, UPEL, enlace Barinas, Venezuela). Actualmente profesor de Ecología, Realidad Nacional y Derecho Constitucional en el Instituto Tecnológico Sudamericano de Cuenca, Ecuador. 
Nacida en San Félix, estado Bolívar, Venezuela.

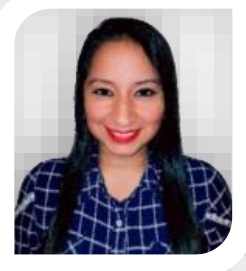
Residenciada en Cuenca, Ecuador. Estudios: Licenciada en Educación Mención Integral (Universidad Nacional Experimental de Los Llanos Occidentales Ezequiel Zamora, UNELLEZ, Barinas, estado Barinas); Experta en Educación Interactiva y a Distancia (Universidad Fermín Toro, UFT). Actualmente docente de aula en la Unidad Educativa Rousseau; Coordinadora del Plan de Prevención de Riesgos (PPR) y responsable del Programa Ambiental Tierra de Niñas y Niños para el Buen Vivir (TINI) a partir del año lectivo 2017-2018, con 8 años de experiencia en el área Educativa. 